\title{
ERROS QUE PODEM SER CORRIGIDOS OU EVITADOS: CONSELHOS DE LEONOR POSADA ÀS MENINAS (DÉCADA DE 1950)
}

\author{
Fernanda Theodoro Roveri ${ }^{1}$
}

\section{RESUMO}

A escritora e professora Leonor Posada (1893-1960) foi uma expressiva colaboradora das revistas infantojuvenis da editora O Malho. Seus textos correspondiam ao propósito dos editores de atingir o público escolar, servindo tanto para o divertimento quanto para a instrução das crianças. O artigo apresenta alguns textos da revista Cirandinha e analisa como eles contribuíram para a educação de meninas durante os anos de 1950. A partir da perspectiva da História Cultural, realiza-se a discussão bibliográfica e a análise de fontes históricas da imprensa escrita. Como resultado, conclui-se que as revistas foram um dos veículos de produção de discursos e de representações sobre a infância, para os quais a participação de Leonor Posada foi essencial na difusão de conselhos e prescrições às meninas.

Palavras-chave: Leonor Posada, revistas infantis, literatura infantil, educação feminina.

${ }^{1}$ Universidade Federal de São Carlos (UFSCAR), São Carlos/SP, Brasil. 


\title{
EQUÍVOCOS QUE PUEDEN SER CORREGIDOS O EVITADOS: CONSEJOS DE LEONOR POSADA PARA LAS NIÑAS (DÉCADA DE 1950)
}

\section{RESUMEN}

La escritora y profesora Leonor Posada (1893-1960) fue una importante colabora de las revistas infantil y juvenil del editorial O Malho. Sus textos correspondían al propósito de los editores de alcanzar al público escolar, teniendo utilidad ya sea como divertimento o como instrucción para los niños. El artículo presenta algunos textos de la revista Cirandinha y analiza como ellos contribuyeron para la educación de niñas durante los años de 1950. A partir de la perspectiva de la Historia Cultural, se realiza una discusión bibliográfica y el análisis de fuentes históricas de la prensa escrita. Como resultado se puede concluir que las revistas fueron un vehículo de producción de discursos y de representaciones sobre la infancia, para los cuales la participación de Leonor Posada fue esencial en la difusión de consejos y prescripciones a las niñas.

Palabras clave: Leonor Posada, revistas infantiles, literatura infantil, educación feminina.

\section{MISTAKES THAT CAN BE CORRECTED OR AVOIDED: LEONOR POSADA'S ADVICES TO GIRLS (1950's)}

\begin{abstract}
The writer and teacher Leonor Posada (1893-1960) was an important contributor to youth magazines from the publishing house $\mathrm{O}$ Malho. Her texts followed the editor's purposes, targeting school children with texts that could be both for their amusement and education. This paper presents some texts from magazine Cirandinha and analyses how they contributed to the education of girls during the 1950's. Based on the perspectives from Cultural History, we did a bibliographic review along with the analysis of historical sources from printed press. As a result, we conclude that the magazines were one of the vehicles that produced discourses and representations about childhood, and the participation of Leonor Posada was essential in the diffusion of advices and prescriptions for girls.
\end{abstract}

Keywords: Leonor Posada, children's magazines, children's literature, girl's education

\section{DES ERREURS QUI PEUVENT ÊTRE CORRIGÉES OU ÉVITÉES : CONSEILS DE LEONOR POSADA AUX FILLES (ANNÉES 1950)}

\section{RÉSUMÉ}

L'écrivain et professeur Leonor Posada (1893-1960) était une importante collaboratrice des magazines jeunesse de la maison d'édition O Malho. Leurs textes correspondaient au but des éditeurs d'atteindre le public scolaire, servant à la fois pour le plaisir et pour l'instruction des enfants. L'article présente quelques textes du magazine Cirandinha et analyse leur contribution à l'éducation des filles au cours des années 1950. Du point de vue de l'histoire culturelle, on fait la discussion bibliographique et l'analyse des sources historiques de la presse écrite. En conséquence, on conclut que les magazines étaient l'un des moyens de production des discours 
et des représentations sur l'enfance, pour lesquels la participation de Leonor Posada était essentielle pour la diffusion des conseils et des ordonnances aux filles.

Mots-clés : Leonor Posada, magazines jeunesse, littérature pour enfants, éducation des femmes. 


\section{INTRODUÇÃO}

Em 1951, o anúncio de uma nova revista destinada exclusivamente às meninas despontava no mercado, era Cirandinha. A publicação, veiculada pela editora O Malho, emergia num cenário de expressiva valorização da vida urbana e dos novos comportamentos a ela associados. Fazia parte das expectativas sociais a definição dos papéis de mulheres e de homens no interior da família e nas distintas esferas da sociedade.

Nesse contexto, a imprensa fazia-se presente na vida cotidiana das grandes cidades, marcando seu ritmo com as notícias, os debates, os conselhos, a literatura e a publicidade. Mais especificamente no que diz respeito às publicações infantojuvenis, seus editores imbuíam-se da missão de colaborar para a escolarização da infância, produzindo um material que divertisse e, ao mesmo tempo, instruísse os leitores, vistos como o futuro promissor da nação.

A produção literária dirigida ao público infantil constitui uma das fontes possíveis para a escrita de uma história da infância, a qual, em grande parte, é produzida pelos adultos. Tal fato implica compreendermos suas motivações, seus pontos de vista e suas idealizações acerca da infância (GOUVEA, 2009; LUCA, 2005; BECCHI, 1998; BRITES, 2000). Para isso, temos como perspectiva teórico-metodológica a História Cultural, que permite a multiplicidade de objetos de pesquisa, de abordagens e do tratamento das fontes, ampliando as análises acerca da dinâmica complexa que envolve as práticas educativas (CARDOSO, 2011). No que diz respeito à imprensa, destacamos sua importância como fonte para a História da Educação, sendo objeto da cultura material que forma leitores, dissemina valores e costumes, prestando-se a diferentes fins e manuseios de públicos distintos.

As revistas, consideradas bens simbólicos, aportam formas específicas de representação, delineiam práticas discursivas e constroem sentidos, produzindo o que Roger Chartier (2002) chama de ordenamento, afirmação, distâncias e divisões. São, portanto, objetos materiais que participam da 
educação dos indivíduos. Suas páginas carregam intencionalidades, anseios e definições sobre o que é ser criança e constituem um real considerado verdadeiro. Como afirmam Soares e Roveri (2013, p.156),

Folhear uma revista infantil nos permite uma aproximação, mesmo que tênue, das expectativas de outros tempos em torno das atitudes esperadas para meninos e meninas. Isso porque as revistas infantis constituíram um dos veículos nos quais discursos que definiam a criança eram produzidos, além de serem espaços para a difusão de um tipo de julgamento do gosto.

Neste artigo apresentamos alguns textos publicados por Leonor Posada na revista infantil Cirandinha, analisando como a escritora contribuiu para a educação de meninas durante os anos de 1950. O objetivo é compreender as representações de feminilidade veiculadas na revista, analisando como estas definem um modo de ser criança num período em que os papéis sociais de homens e mulheres eram distintamente demarcados.

O corpus documental desta pesquisa é formado por artigos de Leonor Posada nos exemplares de Cirandinha da década de 1950. Para uma compreensão das contribuições de Posada no âmbito da educação e da literatura do período, outras obras de sua autoria foram consultadas, bem como artigos de jornais e de revistas publicados no período compreendido entre os anos de 1920 a 1960. O levantamento destas fontes foi realizado na Biblioteca Infantojuvenil Monteiro Lobato - SP e no acervo digital da Fundação Biblioteca Nacional.

Ao folhear as páginas de Cirandinha, é possível observar que os elementos discursivos não estão isolados, mas fazem parte de um conjunto de escolhas feitas pelos editores para que suas publicações fossem acessadas pelo público. Nesse sentido, a revista é tomada aqui como um artefato cultural, o que significa compreender os objetivos que levaram sua circulação em espaços não escolares e escolares. Desde a concepção do que seria a primeira revista para meninas, os editores não só cuidaram da formatação, das capas, das ilustrações e dos textos, como também buscaram estratégias de aproximação com o público 
escolar, o que justifica a importância dada à presença de intelectuais, poetas e professores em suas páginas, como no caso de Leonor Posada.

Para a aceitação por parte das famílias e de educadores, era necessário que Cirandinha se apresentasse ao mesmo tempo como revista recreativa e instrutiva, de leitura saudável e aconselhável na educação das meninas, num cenário editorial em que outras revistas em quadrinhos de super-heróis estrangeiros começavam a ganhar espaço no mercado infantojuvenil brasileiro.

A seguir, discutiremos a trajetória da escritora no âmbito da imprensa e da educação. Em seguida, a partir de histórias veiculadas em Cirandinha, analisaremos a construção de uma representação acerca da identidade feminina. Por fim, apresentaremos algumas considerações sobre a educação do corpo infantil, no que diz respeito aos comportamentos, aos gestos, às falas e aos modos de socialização.

\section{BREVE TRAJETÓRIA DE LEONOR POSADA NA EDUCAÇÃO E NA LITERATURA BRASILEIRA}

Nascida na cidade de Cantagalo, no Rio de Janeiro, no ano de 1893, Leonor Posada foi professora, poeta, dramaturga e jornalista, tendo falecido na capital do estado, em 1960. Formou-se pela antiga Escola Normal do Rio de Janeiro e, nesse período, manteve proximidade com Olavo Bilac e Manoel Bomfim. Parte de sua trajetória como normalista foi narrada pela própria escritora em uma entrevista para o Diário de Notícias, em 1955:

Meu curso na Escola Normal se não foi dos mais brilhantes, também não foi dos fracos. Sem recursos para comprar livros, usando do papel de padaria para meus apontamentos, mantive uma linha de estudiosa ante meus mestres. Lembrá-los com saudade e carinho é meu dever. Mas dois nomes brilham em minhas recordações: o do dr. Sérvulo de Lima, professor de Português, a quem devo o estímulo, o amor e o entusiasmo para com nossa bela língua portuguesa, e Manuel Bomfim, grande psicólogo e pedagogo a quem devíamos belíssimas aulas de 
didática, sem pretensões a renovador, mas em nada diferentes das hoje chamadas - escolas novas! (DIÁRIO DE NOTÍCIAS, 1958, p. 6).

Durante sua atuação no campo da literatura e do ensino, Posada conviveu com diversos escritores de prestígio à época, como Belmiro Braga, Alberto de Oliveira, Coelho Neto, Julia Lopes de Almeida e Gilka Machado. Participou também de programas em rádios, declamando seus versos, e frequentou associações como a Sociedade dos Homens de Letras do Brasil e a Associação Brasileira de Imprensa (FANGUEIRO, 200-; FELGA, 2009).

Tinham lugar de destaque na imprensa do período tanto suas poesias e declamações como também a sua carreira no magistério, conforme abordado pelo tenente Isidro Nunes na seção literária da Revista de Polícia, em 1927:

Professora cathedratica da nossa municipalidade, nomeada em 1907, depois de um concurso em que logrou as mais brilhantes classificações, Leonor Posada tem prestado no magistério os mais assignalados serviços em prol do desenvolvimento da instrucção no Brasil. E, assim, pelo seu talento, pela sua cultura e pelo seu profundo amor ás letras-pátrias, Leonor Posada só tem feito honrar e engrandecer, não só o feliz recanto da terra fluminense em que nasceu - a cidade de Cantagallo, mas também a intellectualidade feminina do Brasil e a sua própria pátria (NUNES, 1927, apud FELGA, 2009, p. 92).

Ao longo de sua vida, Leonor Posada assumiu diversas atividades educacionais: foi diretora de escola aos 17 anos, superintendente de ensino, colaboradora de periódicos como Revista Escola Argentina, Brasil Feminino e das publicações da editora $\mathrm{O}$ Malho, além de autora de numerosas obras didáticas e literárias, como Plumas e Espinhos, Serenidade, Canções Infantis, Quando o Céu se Enche de Balões, Leituras Cívicas, dentre outras. Posada tinha grande prestígio no meio educacional, frequentava os eventos sociais da elite carioca e contava com grande reconhecimento na imprensa, conforme reafirmado pela colega e professora Mariza Lira, em uma publicação no Diário de Notícias (1958), cujo conteúdo destacava suas obras destinadas ao público 
infantil:

Poetisa consagrada, escritora e jornalista, especializou-se em literatura infantil e em livros didáticos de reconhecido sucesso. Colaborou brilhantemente em vários jornais e revistas do Rio, como poetisa, cronista e contista. Sua bagagem literária é grande e preciosa. Ainda há muita coisa inédita. Leonor Posada é uma grande cultura feminina, que honra as letras do Brasil (LIRA, 1958, p.5).

Um dos trabalhos mais significativos da autora foram os manuais escolares para o ensino de redação. Seu livro Os Primeiros Passos na Redação: Exercícios para as Classes Elementares foi publicado na década de 1940 durante a Reforma Capanema. Nele, é possível identificar diversas propostas de narração cujos conteúdos voltam-se à moralização da criança, como mostram os seguintes exemplos:

I- Sumário - Lina ia com várias colegas para a escola. Em caminho, Lina caiu. As outras meninas riram-se. Marta, porém, levantou-a, acariciou-a. Belo coração, o de Marta.

XII - Sumário - Pinote é um menino muito conversador. Por mais que a professora o observe, o menino não se cala. Chegando o fim da semana os colegas tiveram o cartão de comportamento, mas Pinote não o mereceu e, por isso, ficou triste (POSADA, 1956 apud FELGA, 2009, p. 54).

Ao analisar a educação moral na infância durante as primeiras décadas do século XX, Maria Stephanou (2011) identifica que a produção discursiva disseminada por diferentes campos sociais - religioso, escolar e médico, por exemplo - detinha-se aos perigos da ignorância, das práticas perniciosas e descomedidas. Esses discursos buscavam contrapor tais ameaças por meio de exemplos virtuosos, considerados necessários para uma formação sadia dos cidadãos.

Os textos de Posada alcançavam respeitabilidade no meio educacional pois disseminavam virtudes e demais qualidades aspiradas para a formação dos 
alunos. Sua obra, além de corroborar o ideal de moralização da criança, expressava uma concepção de ensino da língua escrita como o modelo padrão. $\mathrm{Na}$ perspectiva defendida pela autora, os professores seriam responsáveis por fiscalizar a língua infantil, corrigindo suas imperfeições e as expressões populares que, ao seu ver, destruíam a beleza da língua. Para ela, a língua dividia-se em escrita - esta seria a expressão da literatura - e a língua falada, que seria a literatura do povo, o folclore (FELGA, 2009).

Na década de 1940, Posada publicou, juntamente com a professora Mariza Lira, a obra Uma, Duas Angolinhas..., cujo propósito era reunir elementos do folclore brasileiro às crianças. $\mathrm{O}$ recebimento da obra por parte da imprensa revela a expectativa de que uma literatura voltada ao divertimento infantil deveria também atrelar-se à educação da criança, como destaca a matéria publicada por Marta Campos (1943) no periódico Dom Casmurro:

\footnotetext{
"Uma, duas angolinhas" é livro de divertir. Mas, como de educadoras que é, não podia deixar de ser, antes de mais nada, livro educativo. E reúne, com felicidade, esses dois predicados que essenciais em um livro de literatura infantil, nem por isso são muito frequentemente encontrados jutos na mesma obra (CAMPOS, 1943, p. 4).
}

Por outro lado, se a literatura não se mostrasse condizente com as expectativas sociais acerca do que era esperado para a educação das crianças, no que concerne à "formação sadia" dos leitores, as críticas não eram poupadas. A matéria A poesia indígena no Ensino Primário, assinada por Terra de Scena, fazia duras críticas aos versos educativos de Posada, vistos como impróprios e danosos à virilidade masculina:

Já tive occasião ha tempos de commentar a maléfica actuação do verso do máu verso, convem accentuar, na formação intellectual da creança brasileira.[...] A sra. Leonor Posada, poetisa das mais eminentes e figura de relevo no magistério publico, também commetteu a suprema"gaffe" de, um livro de leitura para creanças, escrever alguns "versinhos"... O seu "Livro de Nilda" é para o curso Elementar das 
Escolas Primarias. Para creanças jà taludinhas, portanto. Ao acaso lá encontramos á pag. 226 a poesia "A Mão", que descreve o gesto de uma menina pela agulha e pelo bordado, terminando por mandar um menino aprender taes officios absolutamente femininos:

A mão direita brinca e trabalha;

ninguém lhe ralha;

não ha razão.

Costura, leve,

e borda e escreve...

Menino, imita

a destra mão.

Nesse livro a mania de recitar é uma doença. [...] Pobre brasileirinho inocente! Como te intoxicam de versos horríveis, logo ao despontar da tua intelligencia...E ainda não querem que o Brasil seja uma terra de maus poetas... (SCENA, 1928, p. 2).

O trabalho de Leonor Posada como colaboradora, na imprensa, de contos, crônicas e poesias consolidou-se a partir da década de 1930, ganhando posteriormente espaço nas publicações destinadas ao público infantojuvenil, tais como nas veiculadas pela editora O Malho: O Tico-tico, Gramática Infantil pela Imagem, Cirandinha, Pinguinho e Tiquinho. Os textos de Leonor Posada serviam ao propósito dessa editora de manter uma proximidade com a escola, trazendo aos leitores conteúdos escolares e literários os quais, ao mesmo tempo que divertiam, também seriam educativos e utilizáveis pelos professores.

Nesse aspecto, podemos destacar suas poesias, publicadas nas revistas como incentivo à prática de recitação pelas crianças. A poesia Tarde, publicada na seção Para Recitar da revista Cirandinha, constitui um exemplo do ideal literário empregado na educação da infância:

E está no ocaso o sol; morosamente

vai atrás das montanhas se sumindo...

A côr rubra do céu, lá no ocidente

Noutros matizes doces vai fugindo... 
Das casas, as vidraças entreabertas

ofuscam fortemente, semelhando

haver, em cada, um astro cintilando

ou pupilas de estrelas já despertas.

Sôbre a copa das árvores, em tudo,

há uma poeira loura se esbatendo...

Calma-se o ar; vibra no espaço mudo

a saudade do sol que vai morrendo...

Breve, porém, é essa hora de agonia...

A noite baixa lenta, lentamente;

e, na igrejinha ao longe, alvinitente,

o bronze sôa cavo: - Ave-Maria! (POSADA, 1954, p. 8).

Alicerçada no ensino, a imprensa destinada ao público infantil, durante a década de 1950, imbuía-se da tarefa de auxiliar na educação escolar de seus leitores, trazendo uma representação da infância civilizada, educada em família e virtuosa (ROSA, 2002). Como destacam Lajolo e Zilberman (2007), o paradigma literário predominante até o final dos anos de 1950 caracterizava-se pela manipulação da criança e pela manutenção de sua dependência em relação aos adultos:

\footnotetext{
A tendência principal caracterizou-se pela projeção de uma imagem ideal da criança, pautada pelas expectativas do adulto, que a reduziu à condição pueril e à indigência afetiva e intelectual. Disso resulta o reforço da dependência aos mais velhos, casualmente aqueles que geraram a imagem motivadora de identificação (LAJOLO; ZILBERMAN, 2007, p.116).
}

Essa imagem ideal da criança e sua dependência em relação às expectativas dos adultos são aspectos valorizados nos textos e nas imagens da revista Cirandinha. Em suas páginas, a identificação ocorre por meio dos exemplos do bom comportamento exibidos pelas protagonistas das histórias.

A seguir, apresentaremos algumas das contribuições de Leonor Posada 
publicadas nessa revista durante os anos de 1950, analisando os traços marcantes de sua proposta de educação feminina.

\section{APRENDENDO (BONS) MODOS DE SER MENINA}

Cirandinha foi publicada pela primeira vez em 1951, destacando-se como revista pioneira no país voltada só para as meninas. A tiragem era mensal e suas páginas eram coloridas, no formato $23 \mathrm{~cm}$ x $16 \mathrm{~cm}$, com diversos textos informativos, quadrinhos, poesias, histórias, curiosidades, passatempos e ilustrações. Seus conteúdos promoviam o ensino das habilidades domésticas e valorizavam a dedicação ao trabalho e aos estudos, com o objetivo de educar a leitora para suas atividades futuras de dona de casa, mãe e esposa. Os textos e as imagens destacavam as meninas cuidando de plantas e animais, brincando de casinha, ajudando as mães nos trabalhos domésticos, tais como na limpeza, na costura e no cuidado com os irmãos menores (ROVERI, 2014).

Ao tomarmos as revistas infantis como fontes de pesquisa sobre a infância, buscamos refletir sobre os discursos literários, bem como responder a indagações acerca das formas com que eles produzem uma narrativa sobre as crianças. Essas fontes oriundas da imprensa escrita possibilitam não apenas informações sobre seus conteúdos e projetos educativos, mas, sobretudo, um olhar para a cultura material, já que são objetos que condensam práticas culturais, intenções, regulações e estratégias de seus produtores (ROCHA, 2017).

É importante destacar que os discursos veiculados nas revistas, em sua maior parte, são elaborados pelos adultos e participam da construção de um imaginário sobre a infância. Como destaca Gouvea (2009), nos diversos documentos produzidos para normatizar as práticas e os cuidados com as crianças, os adultos projetam uma determinada representação acerca da identidade infantil e, ao mesmo tempo, estabelecem as estratégias de formação 
e de intervenção educativas.

A partir disso, podemos perguntar: qual representação da infância os textos de Leonor Posada, na revista Cirandinha, produziram? E, mais especificamente, qual era a educação que a escritora projetava às meninas?

Nos editoriais dessa revista, os discursos voltavam-se ao ideário de proteger a criança daquilo que se considerava imoral ou inadequado para uma menina. Um dos textos, por exemplo, alertava as leitoras de que "fica muito feio para uma menina, falar alto, rir descomedidamente, agitar-se e chamar sobre si a atenção pela falta de recato e equilíbrio. Podemos achar graça em algo, e rir, mas nunca às gargalhadas. Essas ficam bem em quem não tem educação. Nunca em uma menina educada" (CIRANDINHA, 1956, p. 3).

É possível perceber, em uma das seções escritas por Leonor Posada, intitulada Erros que Podem ser Corrigidos ou Evitados, o esforço de definir códigos de condutas para a leitora espelhar-se e ser uma "menina educada". A cena escolhida por Posada é o interior do bonde. A primeira ilustração traz duas alunas dentro do veículo voltando da escola, sentadas com desleixo e falando mal de seus professores. O diálogo representa o que seria característico em meninas "grosseiras": falar alto, chamando a atenção de todos:

\footnotetext{
- Maria, tua professora é camarada?

- Não, é uma velha ranzinza!... Não dá uma folga! Então, para casa... É só lição, lição que não acaba mais.

- Puxa! É crente...

- Nada! É Caxias!

- Ah! Ah! Ah! (POSADA, 1955a, p. 12).
}

Leonor Posada chama atenção para o cuidado que a menina deve ter ao comportar-se em público, destacando que meninas delicadas, gentis e ajuizadas sabem manter uma conversa "a meia voz" e aproveitam o tempo do transporte para estudar as lições, não criticando seus mestres: "Não converse, pois, alto, no 
bonde; não critique os mestres e, principalmente, não use termos de gíria" (POSADA, 1955a, p. 12). Para reforçar o comportamento adequado às meninas no espaço público, uma segunda ilustração traz duas meninas sentadas e obedientes, cujo diálogo repara a cena vista anteriormente:

Veja agora estas outras meninas; conversam a meia voz, sem chamar a atenção de pessoa alguma e até parecem duas mocinhas, tão ajuizadas se comportam fora de casa:

- Amanhã terei prova mensal.

- Eu também. Mas não tenho mêdo. D. Alice já ensinou todo o programa...

-É o que digo a respeito de D. Dolores: é severa mas justa e ensina admiravelmente.

- Vamos aproveitar a viagem lendo alguns pontos?

- Ótimo! Vai ver como o tempo passará depressa... (Idem, p. 12).

Em outro texto, na mesma seção, Leonor Posada ensina as leitoras a se comportarem adequadamente na rua. A autora descreve cenas em que meninas se deslocam para a escola e mostra o que é correto e o que é repugnante para uma menina no espaço público. Posada sublinha a necessidade de andar sem chamar atenção, jamais correndo e causando impressões desagradáveis:

Ao ir para a escola, ou no regresso ao lar, deve a menina fazê-lo, a passo, naturalmente, conversando com as coleguinhas, mas nunca a correr como um garoto mal educado... Quantos riscos corre uma menina correndo pelas ruas, às tantas, a rir, sem modo algum? E que impressão má deixa no espírito de todos aqueles que a vêm? (POSADA, 1955b, p. 16).

As atitudes reforçadas às meninas fazem parte de um conjunto de expectativas dos editores da revista em atingir o público leitor e de corresponder aos ideais esperados pela sociedade em relação à educação feminina. $\mathrm{O}$ discurso que a autora elabora sobre a infância indica a visão de que esta necessita ser contida, regrada e adequada a um certo padrão de civilidade adulto, para o qual 
o riso e a alegria deveriam ser controlados. Desse modo, a característica da austeridade era valorizada para que uma menina se transformasse numa futura "dama”.

Nesse aspecto, ao retomarmos as narrativas de Leonor Posada sobre suas memórias como aluna na escola primária, percebemos que aquilo que ela prescreveu às leitoras da revista Cirandinha condiz exatamente com suas atitudes pessoais em relação aos professores e aos estudos:

Frequentei uma só escola primária, a que funcionava num grande prédio de dois andares, na rua da Constituição. Sua diretora - d. Ana Dias Vieira - além de culta e brilhante, era uma austera figura de dama que se impunha, logo à primeira vista. Todos nós temíamos suas censuras, sempre justas; da mesma forma, amávamos seus elogios. Quanto devo em estímulo e apreço a sempre querida e lembrada d. Aninha! (DIÁRIO DE NOTÍCIAS, 1958, p. 6).

Na mesma entrevista, Posada valoriza as posturas de suas professoras e destaca um conjunto de gestos, movimentos e tom de voz que, para ela, foram elementos marcantes nessas figuras femininas. Características como essas também foram reiteradas em seus textos publicados em Cirandinha:

A outra figura inesquecível é a de d. Jesuína, minha amada professora. Seu nome e sua pessoa bem se condiziam com seu divino homônimo: ela era suave, doce, persuasiva. Não andava entre os bancos: antes deslizava, tal a doçura de seus passos, a harmonia de seus gestos. Era modesta, pobre de beleza e bens materiais, mas que riqueza imensa em seu coração! (Idem, p. 6).

As memórias da professora primária, de seus gestos e características pessoais representam imagens idealizadas do magistério feminino. Ao analisar a construção da figura da normalista entre o final do século XIX e início do século XX, Reis (1994) observa que, nos discursos das escolas normais, a imagem da professora era aproximada à de uma imagem religiosa, quase divina. Os atributos valorizados estavam associados aos deveres, abnegações e sacrifícios, 
qualidades também fortemente associadas à figura da mãe. Era esperado que a professora estendesse à escola seu papel exercido no lar (REIS, 1994).

As descrições das figuras femininas presentes nas memórias e nos textos de Posada - fossem meninas, alunas, professoras, diretoras ou mães -, longe de serem meras exposições acerca de seus modos de ser, funcionam como representações, ou seja, prescrevem o significado do feminino. Nesse sentido, os "erros que podem ser corrigidos e evitados" pelas meninas dizem respeito a um conjunto de normas minuciosas acerca da postura, da vestimenta, dos gestos, da altura da voz, do movimento e do tipo de conversa permitida em público. Ademais, sinalizam o aproveitamento útil e saudável do tempo nos deslocamentos, seja dentro do bonde, seja caminhando na rua. Essas prescrições ao corpo feminino confirmam o que Becchi (2003) chama de interdição da palavra na educação das meninas:

Suspeitas de falarem demais e sem razão, consideradas como incapazes de raciocínio, vistas como propensas ao pecado e, de qualquer maneira, frágeis, exatamente pela sua essencial natureza infantil, que persiste mesmo ao crescer, as mulheres, na primeira infância, são mantidas no e em silêncio (BECCHI, 2003, p.42).

A educação desejável à menina que transita nos espaços públicos faz-se por meio do silenciamento e do controle dos gestos, do riso e dos movimentos. A revista compara, diferencia e delimita os comportamentos femininos e masculinos nesses locais, revelando o quanto a presença da menina era vista com cuidado e com ressalvas no espaço público.

Conforme discute Yannoulas (2012), especialmente a partir do século XIX, no Ocidente, observamos uma construção discursiva que estabelecia identidades diferenciadas ao feminino e ao masculino. De acordo com a autora, a identidade feminina foi constituída discursivamente com base numa argumentação biológica, segundo a qual as mulheres deveriam exercer sua função reprodutiva, dedicando-se ao lar e à família, e uma argumentação 
essencialista, a qual atribuía às mulheres características cristalizadas em uma essência natural: fraqueza, irracionalidade, afetividade etc. Tais discursos corroboraram a disseminação de um ideal feminino, voltado à maternidade e à esfera privada. Com base nesse ideal, foi legitimada a exclusão das mulheres em diversos âmbitos como, por exemplo, nos da política e do trabalho.

Por outro lado, a identidade masculina foi construída discursivamente com base na argumentação política, ou seja, nas funções produtivas e públicas que o homem deveria ter na sociedade, e na argumentação essencialista, a qual lhe atribuiu características como força, agressividade, racionalidade, independência, dentre outras.

A imagem da infância veiculada na imprensa da década de 1950 estava atrelada às representações de feminilidade e de masculinidade, bem como aos padrões sociais adultos. As crianças ilustradas compunham esses ideais e, ainda, "eram definidas como 'distintas e de bom-gosto', felizes, comportadas, inteligentes, estudiosas, sadias e limpas, elementos que as destacariam como membros de uma vida urbana e escolarizada" (ROVERI, 2014, p. 42).

As meninas leitoras de Cirandinha, portanto, teriam em mãos um instrumento para avaliar e corrigir o próprio comportamento, a fim de incorporar os exemplos de conduta trazidos pelos adultos. Muitas dessas lições, elaboradas por educadores e escritores como Leonor Posada, ensinavam a criança a ser obediente e agir conforme os valores sociais, preparando-se para as responsabilidades adultas. Vale destacar que essas responsabilidades também fizeram parte da vida pessoal da autora. Em entrevista, Posada desabafou o quanto para ela foi difícil abnegar-se de sua juventude e silenciar seus prazeres para assumir sua carreira no magistério:

Quando fui nomeada diretora de escola, minha mãe e meu padrasto, felizes, abraçaram-me muito: depois chamaram-me e me deram conselhos relativos à minha nova posição: "Não poderia passear na calçada, como era moda às mocinhas; não poderia mais dançar; nem rir alto, nem tomar parte em festas, mesmo familiares: era diretora da escola: tinha grandes responsabilidades". E, enquanto minhas amigas, 
nos bailes, riam e dançavam felizes, eu, no sofá em companhia das senhoras e dos homens respeitáveis tomava parte nas longas conversas sobre a vida, costumes, política, que sei eu! Nesses momentos, como ia longe a minha pobre e louca imaginação! (DIÁRIO DE NOTÍCIAS, 1958, p. 6).

Ao trazermos aqui uma breve história da professora Leonor Posada a partir de suas memórias, produções e presença nos meios de comunicação da década de 1950, buscamos também construir um olhar para as mulheres como sujeitos históricos. Nesse sentido, vale refletirmos, conforme destaca Rago (1995, p. 81), que a "História não narra o passado, mas constrói um discurso sobre este, trazendo tanto o olhar quanto a própria subjetividade daquele que recorta e narra, à sua maneira, a matéria da história”. Sublinhamos, assim, a existência de relações de gênero e de múltiplos jogos de significações e de poder que se estabelecem nas configurações discursivas acerca dos sujeitos femininos aqui analisados. Desse modo, podemos dizer que os discursos produzidos nos textos e nas imagens da revista Cirandinha fazem parte de um amplo conjunto de representações no qual se mesclam os pontos de vista e experiências pessoais de seus autores, bem como os ideais do público leitor, de suas famílias, professores e da sociedade em geral. A trajetória de Leonor Posada na imprensa e na literatura educacional certamente traz indícios dos anseios, das ambivalências e das contradições que perpassam esses discursos.

\section{CONSIDERAÇÕES FINAIS}

As revistas infantis da editora O Malho constituíram um dos veículos de produção de narrativas que definiam e projetavam idealizações sobre a criança, tendo como suporte o trabalho da professora Leonor Posada, cujas publicações propunham difundir crenças, valores, normas e prescrições de comportamento às meninas. A palavra escrita e as imagens veiculadas em Cirandinha foram selecionadas e ordenadas de modo a compor narrativas e representações acerca 
do ser criança naquele período e naquela sociedade.

A presença da literatura com forte viés conservador e atrelada às funções pedagógicas e moralizantes confirma-se como uma escolha de seus editores, o que é visível em um dos anúncios de venda da revista: "Páginas rigorosamente cuidadas, onde os pequenos leitores encontram divertimento e sadias lições e onde os professores deparam excelente material utilizável nas suas classes” (CIRANDINHA, 1953). Desse modo, fica evidente a intencionalidade dos editores em contar com as colaborações da professora e escritora Leonor Posada, cujo nome já detinha um prestígio social, o que certamente permitiria maior confiança e carisma da revista entre seu público leitor.

As meninas boazinhas ilustradas em Cirandinha tentavam se sobressair ao crescimento de publicações voltadas ao divertimento, como os gibis norteamericanos Pato Donald e Mickey, por exemplo. Apesar da desaprovação das histórias em quadrinhos por parte de intelectuais e de educadores, o mercado editorial brasileiro foi alavancado pela publicidade e pela presença dos superheróis nas diversas mídias, fazendo com que, no final da década de 1950, as revistas da Editora O Malho começassem a perder seu público para os gibis.

Se o viés conservador defendia a proteção da menina daquilo que se considerava leitura perversa e não edificante, para isso, a estratégia escolhida era o resguardo da menina no espaço privado, atrelado à abnegação e ao sacrifício. Ao ensinar a leitora a se comportar com obediência nos locais públicos, como nas escolas, nas ruas, nos meios de transporte e em outras situações cotidianas, a revista prescrevia a contenção de seus gestos e sentimentos, além do purismo da fala, da aparência e da indumentária.

Os dados levantados nesta pesquisa confirmam que tais características defendidas para a educação feminina se fizeram presentes na vida pessoal da escritora Leonor Posada. Nos depoimentos da autora acerca de sua própria infância e juventude, ela sinalizava experiências de tristeza advindas da necessidade de abnegação de sua juventude e de sacrifício pessoal pelo 
magistério. Ao ser chamada para fazer parte da produção de uma primeira revista de variedades para meninas, certamente Posada tinha muito a dizer de si mesma a essas leitoras. As análises das cenas escolares e de convívio social presentes em seus textos mostram uma proximidade com o que a escritora relatou ter vivido e sentido quando mais jovem.

Assim, é possível afirmar que durante toda sua trajetória na imprensa, Leonor Posada contribuiu para a educação moral, literária e patriótica das crianças, prestando também auxílio pedagógico aos professores. A presença da escritora na produção de uma revista destinada a educar e a divertir certamente corrobora o ideal de seus editores, que era oferecer uma instrução saudável e contribuir para a educação escolar e familiar das meninas, vistas não como crianças, mas como futuras mulheres, em suas funções cívicas, maternais e domésticas.

\section{REFERÊNCIAS}

A MANHÃ. Rio de Janeiro, n. 912, 28 nov. 1928.

BECCHI, Egle. Le XXe siècle. In : BECCHI, Egle; JULIA, D. (orgs.). Histoire de l'enfance en occident: Du XVIIIe siècle à nos jours. Paris: Éditions du Seuil, 1998. t. 2, p. 358-433.

BECCHI, Egle. Ser menina ontem e hoje: notas para uma pré-história do feminino. Pro-Posições, Campinas, v. 14, n. 3, p. 41-52, set./dez. 2003. Disponível em:

https://periodicos.sbu.unicamp.br/ojs/index.php/proposic/article/view/86438 6o/11337. Acesso em: 4 mar. 2019.

BRITES, Olga. Crianças de revistas (1930/1950). Educação e Pesquisa, São Paulo, v. 26, n. 1, p. 161-176, jan./jun. 2000. Disponível em: http://www.scielo.br/scielo.php?script=sci_arttext\&pid=S151797022000000100011\&lng=pt\&nrm=iso. Acesso em: 7 mar. 2019.

CAMPOS, Marta. Uma, duas angolinhas. Dom Casmurro, Rio de Janeiro, ano VII, n. 331, p. 4, 11 dez. 1943,. 
CARDOSO, Maurício Estevam. Por uma história cultural da educação: possibilidades de abordagens. Cadernos de História da Educação, Uberlândia, v. 10, n. 2, p. 287-302, jul./dez. 2011. Disponível em: http://www.seer.ufu.br/index.php/che/article/view/14627. Acesso em: 7 mar. 2019.

CHARTIER, Roger. A História Cultural: entre práticas e representações. 2. ed. Lisboa: Difel, 2002.

CIRANDINHA. Rio de Janeiro, ano 3, n. 30, set. 1953.

CIRANDINHA. Rio de Janeiro, ano 4, n. 40, jul. 1954.

CIRANDINHA. Rio de Janeiro, ano 5, n.50, mai. 1955a.

CIRANDINHA. Rio de Janeiro, ano 5, n.53, ago.1955b.

CIRANDINHA. Rio de Janeiro, ano 6, n. 63, jun.1956.

DIÁRIO DE NOTÍCIAS. Rio de Janeiro, n.11022, 19 out. 1958. Suplemento literário.

DOM CASMURRO. Rio de Janeiro, ano 7, n. 331, 11 dez. 1943.

FANGUEIRO, Maria do Sameiro. Leonor Posada. In: BRASIL. Fundação Biblioteca Nacional. Projeto Periódicos \& Literatura: publicações efêmeras, memória permanente. [200-]. Disponível em: <https://bndigital.bn.gov.br/dossies/periodicos-literatura/personagensperiodicos-literatura/leonor-posada/>. Acesso em 07 mar. 2019.

FELGA, Tatiana Emanuele Brito. Manuais de redação de Leonor Posada: as concepções de língua e as propostas de ensino para a produção textual. 2009. 100 f. Dissertação (Mestrado em Língua Portuguesa) - Pontifícia Universidade Católica de São Paulo, São Paulo, 2009. Disponível em: https://tede2.pucsp.br/handle/handle/14600. Acesso em: 1 mar. 2019.

GOUVEA, Maria Cristina Soares de. A escrita da história da infância: periodização e fontes. In: SARMENTO, Manuel; GOUVEA, Maria Cristina Soares de (orgs.). Estudos da infância: educação e práticas sociais. 2. ed. Petrópolis, RJ: Vozes, 2009. p. 97-118.

LAJOLO, Marisa; ZILBERMAN, Regina. Literatura infantil brasileira: história e histórias. São Paulo: Ática, 2007.

LIRA, M. Canções infantis. Diário de Notícias, Rio de Janeiro, n. 11022, 19 out. 1958. Suplemento literário, p.5. 
LUCA, Tania Regina de. História dos, nos e por meio dos periódicos. In: PINSKY, Carla Bassanezi (org.). Fontes Históricas. São Paulo: Contexto, 2005. p. 111-153.

POSADA, Leonor. Erros que podem ser corrigidos ou evitados: no bonde. Cirandinha, ano 5, n. 50, p. 12, mai. 1955a.

POSADA, Leonor. Erros que podem ser corrigidos ou evitados: na rua. Cirandinha, ano 5 , n. 53, p. 16, ago.1955b.

POSADA, Leonor. Tarde. Cirandinha, ano 4, n. 40, p. 8, jul. 1954.

RAGO, Margareth. As mulheres na historiografia brasileira. In: SILVA, Zélia Lopes da (org.). Cultura histórica em debate. São Paulo: Unesp, 1995. p. 81-91.

REIS, Maria Cândida Delgado. Guardiãs do futuro: imagens do magistério de 1895 a 1920 em São Paulo. In: BUSCHINI, Cristina e SORJ, Bila (orgs.). Novos olhares: mulheres e relações de gênero no Brasil. São Paulo: Fundação Carlos Chagas; Marco Zero, 1994. p. 111-132.

ROCHA, Heloísa Helena Pimenta. Regras de bem viver para todos: a "Bibliotheca Popular de Hygiene” do Dr. Sebastião Barroso. Campinas: Mercado de Letras, 2017.

ROSA, Zita de Paula. O Tico-Tico: meio século de ação recreativa e pedagógica. Bragança Paulista: Edusf, 2002.

ROVERI, Fernanda Theodoro. Criança, o botão da inocência: as roupas e a educação do corpo infantil nos “anos dourados". 2014. 190f. Tese (Doutorado em Educação) - Faculdade de Educação, Unicamp, Campinas, 2014.

SCENA, Terra de. A poesia indígena no ensino primário. A Manhã, Rio de Janeiro, n. 912, 28 nov.1928. p. 2.

SOARES, Carmen Lúcia; ROVERI, Fernanda Theodoro. Entre laços, rendas e fitas, onde estão os botões? As roupas de crianças e a educação do corpo (década de 1950). ArtCultura, Uberlândia, v. 15 n. 26, p. 153- 168, jan./jun. 2013.

STEPHANOU, Maria. O que um menino deve saber para seu bem: representações de infância em manual de educação moral e sexual do início do século 20. Revista História da Educação, Santa Maria, v. 15, n. 33, p. 63-87, jan./abr. 2011. Disponível em: https://seer.ufrgs.br/asphe/article/view/20101. Acesso em: 22 abr. 2019.

YANNOULAS, Silvia Cristina. Feminização ou feminilização? Apontamentos em 
torno de uma categoria. Temporalis, Brasília, ano 11, n. 22, p. 271-292, fev. 2012. Disponível em: http://periodicos.ufes.br/temporalis/article/view/1368. Acesso em: 27 abr. 2019.

Fernanda Theodoro Roveri é doutora em educação pela Unicamp, na linha Educação e História Cultural. Atualmente é professora de Educação Infantil e no curso de Pedagogia da Universidade Federal de São Carlos (Campus Sorocaba).

E-mail: ferdth@yahoo.com.br

(b) http://orcid.org/0000-0002-2916-6827

Recebido em: 04 de maio de 2019

Aprovado em: 21 de novembro de 2019

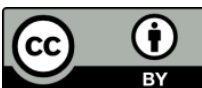

Revista História da Educação - RHE

Associação Sul-Rio-Grandense de Pesquisadores em História da Educação - Asphe

Artigo de acesso aberto distribuído nos termos de licença Creative Commons. 